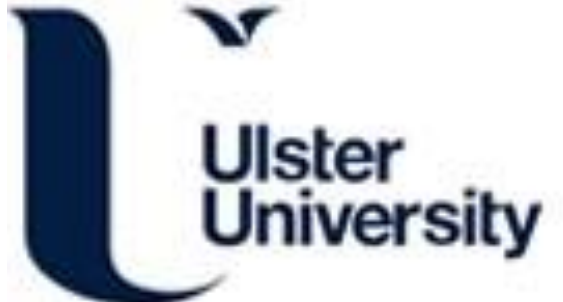

\section{Control of magnesium alloy corrosion by bioactive calcium phosphate coating: Implications for resorbable orthopaedic implants}

Acheson, J., McKillop, S., Lemoine, P., Boyd, A., \& Meenan, BJ. (2019). Control of magnesium alloy corrosion by bioactive calcium phosphate coating: Implications for resorbable orthopaedic implants. Materialia, 6(C), 1-10. [100291]. https://doi.org/10.1016/j.mtla.2019.100291

Link to publication record in Ulster University Research Portal

Published in:

Materialia

Publication Status:

Published (in print/issue): 30/06/2019

DOI:

10.1016/j.mtla.2019.100291

\section{Document Version}

Author Accepted version

\section{General rights}

Copyright for the publications made accessible via Ulster University's Research Portal is retained by the author(s) and / or other copyright owners and it is a condition of accessing these publications that users recognise and abide by the legal requirements associated with these rights.

\section{Take down policy}

The Research Portal is Ulster University's institutional repository that provides access to Ulster's research outputs. Every effort has been made to ensure that content in the Research Portal does not infringe any person's rights, or applicable UK laws. If you discover content in the Research Portal that you believe breaches copyright or violates any law, please contact pure-support@ulster.ac.uk. 
Control of Magnesium Alloy Corrosion by Bioactive Calcium Phosphate Coating: Implications for Resorbable Orthopaedic Implants.

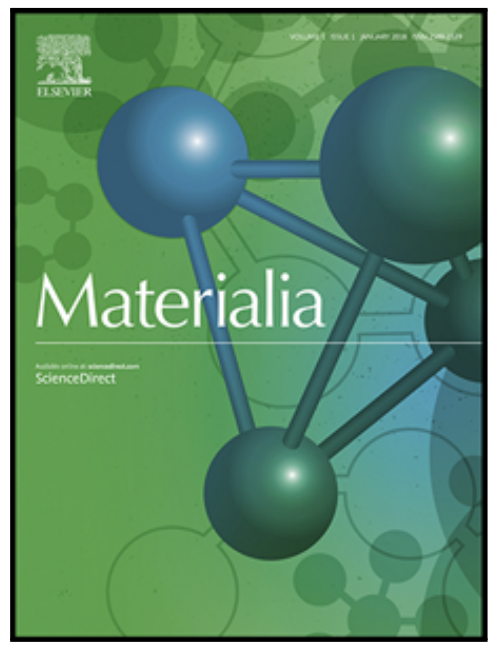

J Acheson, S. McKillop, P. Lemoine, A.R. Boyd, B.J. Meenan

PII: S2589-1529(19)30087-0

DOI: https://doi.org/10.1016/j.mtla.2019.100291

Article Number: $\quad 100291$

Reference: $\quad$ MTLA 100291

To appear in: Materialia

Received date: $\quad 3$ January 2019

Accepted date: $\quad 10$ March 2019

Please cite this article as: J Acheson, S. McKillop, P. Lemoine, A.R. Boyd, B.J. Meenan, Control of Magnesium Alloy Corrosion by Bioactive Calcium Phosphate Coating: Implications for Resorbable Orthopaedic Implants., Materialia (2019), doi: https://doi.org/10.1016/j.mtla.2019.100291

This is a PDF file of an unedited manuscript that has been accepted for publication. As a service to our customers we are providing this early version of the manuscript. The manuscript will undergo copyediting, typesetting, and review of the resulting proof before it is published in its final form. Please note that during the production process errors may be discovered which could affect the content, and all legal disclaimers that apply to the journal pertain. 


\title{
Control of Magnesium Alloy Corrosion by Bioactive Calcium Phosphate Coating: Implications for Resorbable Orthopaedic Implants.
}

\author{
J Acheson*, S. McKillop, P. Lemoine, A.R. Boyd, B.J. Meenan
}

Nanotechnology and Integrated Bioengineering Centre (NIBEC), School of Engineering, Ulster University, Shore Road, Newtownabbey, Co Antrim BT37 OQB, Northern Ireland, UK.

*Corresponding Author: j.acheson@ulster.ac.uk, Tel: +44 (0)28 90368663

\section{Graphical Abstract:}
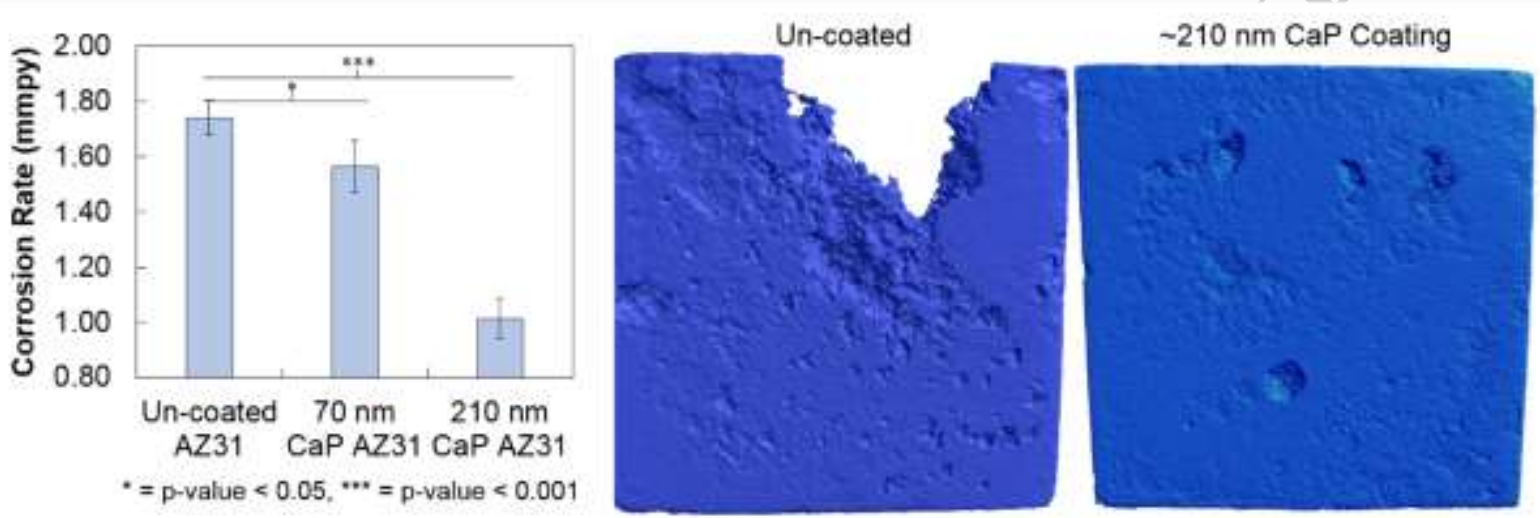

\begin{abstract}
:
Control of the corrosion that occurs in magnesium alloys in vivo is a significant challenge for their use as resorbable orthopaedic implants. In this work, we report on the provision of bioactive calcium phosphate $(\mathrm{CaP})$ coatings on magnesium alloys that can delay substrate corrosion while offering an attendant physiochemical environment with properties known to promote an osteoinductive response in vivo. RF magnetron sputtering from hydroxyapatite (HA) powder targets has been employed to create CaP coatings on AZ31 magnesium alloy substrates. Coatings of 70 and $210 \mathrm{~nm}$ thickness were achieved via regulation of sputtering parameters, in particular deposition time. XPS and ToF-SIMS were used to investigate the chemistry of the coating alloy interface and also to confirm composition and thickness. The $\mathrm{Ca} / \mathrm{P}$ atomic ratio of the coatings was determined by EDX to be 1.54. $\mu \mathrm{CT}$ analysis showed a substrate volume loss after 14 days exposure to SBF of $5.89 \pm 3.15 \mathrm{~mm}^{3}$ for the un-coated alloy while the presence of the $\sim 70 \mathrm{~nm} \mathrm{CaP}$ coating reduced this to $3.42 \pm 0.48 \mathrm{~mm}^{3}$ and the $\sim 210 \mathrm{~nm}$ coating to $0.30 \pm 0.28 \mathrm{~mm}^{3}$. The corrosion rates were calculated to be $1.74 \pm 0.06$ mmpy for the AZ31 control; $1.57 \pm 0.09 \mathrm{mmpy}$ for the $\sim 70 \mathrm{~nm} \mathrm{CaP}$ coated alloy and $1.01 \pm$ 0.07 mmpy for the $\sim 210 \mathrm{~nm}$ thick $\mathrm{CaP}$ coating. These data confirm that $\mathrm{CaP}$ coating
\end{abstract}


thickness can control the rate of corrosion of magnesium alloys while offering the potential for improved bioactivity.

\section{Keywords:}

Magnesium alloy, RF magnetron, Calcium phosphate Coatings, Corrosion, Biomaterial.

\section{Introduction}

The current generation of orthopaedic implants used for the stabilisation and repair of complex bone fractures are fabricated from a range of stable bioinert alloys such as stainlesssteel, titanium aluminium vanadium and cobalt chromium [1]. Although such devices are in the main successful as permanent long-term implant materials, there are significant limitations to their use as temporary fixation, especially in cases of high energy trauma (traffic accidents, falls from height, sports injuries, etc.) and for treatment of osteoporotic fractures in the elderly [2,3]. In particular, the need for a secondary surgery [4] and the associated increased risk of infection and várious other complications associated with such surgeries have been noted [5,6]. Moreover, the mechanical properties of the current bioinert metal alloy systems are not always ideal for bone fixation, and in some cases can release potentially toxic and irritating metal particulates $[7,8]$. By contrast, magnesium alloys offer high ductility, high strength and fracture toughness properties commensurate with that of bone and, importantly, can undergo complete resorption after fracture healing $[9,10]$. As such, an orthopaedic implant device composed of a magnesium alloy would not need a second surgery for its subsequent removal. This coupled with the potential of magnesium to directly promote tissue repair offers a significant advantage over the current generation of metal/metal alloy implants $[11,12]$. Hence, a range of magnesium alloy systems are currently being developed as materials for the fabrication of bioresorbable orthopaedic implants to replace permanent metal alloys in applications ranging from thin wires to thicker pins, rods, screws and elastic stable intramedullary nails (ESINs) [13-15]. 
A key consideration for the use of magnesium alloys as biomaterials for the fabrication of resorbable bone fixation implants is control of their effective dissolution rate in vivo, commonly referred to as the corrosion rate $[16,17]$. Whereas, a high degree of corrosion control can be achieved by varying the alloy composition this is limited significantly by the need to deliver the requisite mechanical properties, specifically adequate strength and flexibility to support surgical implantation [18,19]. An alternative means of controlling magnesium alloy corrosion is via the use of a barrier coating material which prevents the agents of corrosion reaching the implant surface [20-22]. However, as these implants are explicitly designed to be fully resorbed by the body, complete resistance to corrosion is counter indicative. Hence, the coatings themselves need to degrade while offering a means of corrosion control such that their resistance to the environment is different than that of the underlying alloy. Recent work shows the deposition of a range of barrier coatings from zinc [20] to layer-by-layer coatings which incorporate DNA [22], among others [23-25]. Clearly, the degradation products produced by such coated alloys must be biocompatible and ideally bioactive [26].

In this paper, we report that $\mathrm{RF}$ magnetron sputtered bioactive $\mathrm{CaP}$ coatings formed on magnesium alloys can delay the onset of corrosion significantly. CaP coatings have been deposited onto magnesium alloys previously for the purposes of improved corrosive properties, using a variety of methods [21,27-29], however there is a limited understanding of how dense) $\mathrm{RF}$ magnetron sputtered $\mathrm{CaP}$ thin films impact corrosion. The coatings are designated herein as being $\mathrm{CaP}$ in nature as they have a slightly different stoichiometry than that of the hydroxyapatite (HA) powder targets from which they are formed [30-32]. Notwithstanding this slight chemical difference, they are capable of offering an attendant physiochemical environment with properties that are known to promote an osteoinductive response in vivo [33,34]. Specifically, these resorbable CaP coatings can be used to solicit 
control over the rate of magnesium alloy corrosion while at the same time offering an enhanced bioactive environment at the site of implantation. In this regard, previous studies have shown that this type of $\mathrm{CaP}$ coating can actively promote the recruitment and differentiation of bone cells leading to new tissue formation and stable fixation of traditional orthopaedic implants [33]. By controlling both the composition of the sputter target material, typically medical grade hydroxyapatite (HA), and the sputter deposition parameters, the chemical and microstructural properties of the resulting $\mathrm{CaP}$ layer can be varied in terms of thickness and subsequently the rate of dissolution $[35,36]$. In addition, it has been determined that the topographical microstructure of the $\mathrm{CaP}$ coating surface plays a role in its subsequent dissolution rate and thereby on the onset of the attendant magnesium alloy corrosion $[37,38]$. This work highlights the use of RF magnetron sputtering to create $\mathrm{CaP}$ coatings on magnesium alloys, this method is an alternative to those shown previously $[21,39,40]$, offering a dense homogenous protective layer which can be tailored with a controlled dissolution rate [41] and subsequently magnesium alloy corrosion. The coating that has been developed here offers the convergent advantages of resorbable orthopaedic fracture fixation and creation of implant-tissue environment that can actively support rapid bone formation.

\section{Materials and Methods}

2.1. Sample Preparation

A commercial grade magnesium (aluminium, zinc) alloy, AZ31, nominal composition: $96 \% \mathrm{Mg}, 3 \% \mathrm{Al}, 1 \% \mathrm{Zn}$ (Goodfellow Ire.), was used to create coupons of dimensions 10mm $\mathrm{x} 10 \mathrm{~mm} \times 1 \mathrm{~mm}$ which were manually abraded on all faces using p1200 SiC paper (RSComponents, UK). Coupons were ultrasonically cleaned in 99\% isopropanol (Sigma Aldrich, UK) for 30 seconds before being left to dry in air. Samples were then stored in a desiccator at approx. 30\% relative humidity until required. Hydroxyapatite (HA) sputter targets were 
prepared using a dry pressing method as follows: $11.5 \mathrm{~g}$ of medical grade HA (Plasma Biotal Captal-R, UK) was weighed out for each individual sputtering target and pressed into a recessed copper disk using a custom-made stainless-steel die at a load of $80 \mathrm{kN}$. Targets were wrapped in aluminium foil and kept in a drying oven at $60^{\circ} \mathrm{C}$ prior to being placed in the RF magnetron sputter deposition system.

\subsection{RF Magnetron Sputter Coating}

RF magnetron sputtering was carried out using a custom-built high vacuum physical deposition system configured with two circular high vacuum Torus ${ }^{\top \mathrm{M}}$ magnetron sputter sources (Kurt J. Lesker, USA) configured at an incident angle of $45^{\circ}$ below a rotating sample holder, as described in detail elsewhere $[42,43]$. Each Torus ${ }^{\mathrm{TM}}$ source is powered by an RF generator operating at $13.56 \mathrm{MHz}$ coupled with an individual matching network (Huttinger, $\mathrm{GmbH}$, Germany) to minimise reflected power during operation. Coatings were deposited onto all faces of the magnesium alloy coupons with deposition of $\mathrm{CaP}$ coatings conducted in accordance with the parameters provided in Table 1. Carbon tape was used to fix the samples in place during the sputtering process, this was removed carefully with iso propyl alcohol post-sputtering.

Table 1 RF magnetron sputtering parameters used for the deposition of CaP coatings onto AZ31 magnesium alloy surfaces.

\begin{tabular}{lr}
\hline Sputtering Parameter & Setting \\
\hline Power & $150 \mathrm{~W}$ \\
Ramp-up power & $1 \mathrm{~W} / \mathrm{sec}$ \\
Time & $10 \mathrm{~h}$ and $30 \mathrm{~h}$ \\
Chamber pressure & $5 \times 10^{-5} \mathrm{mbarr}$ \\
Working gas & Argon $(99.995 \%)$ \\
Gas flow rate & $32-35 \mathrm{Sccm}$ \\
Throw distance & $100 \mathrm{~mm}$ \\
\hline
\end{tabular}

\subsection{Immersion Corrosion/Dissolution Testing}


The nature and scale of the dissolution of the CaP coatings and the subsequent corrosion of the AZ31 alloy when exposed to aqueous media was determined via in vitro immersion testing in simulated body fluid (SBF). The SBF was produced according to the method described by Kokubo et. $\mathrm{Al}$ [44] and the relative concentration of the SBF constituents are provided in Table 2, with ion concentration of blood plasma provided by way of comparison.

Table 2 Composition of simulated body fluid (SBF) with that of blood plasma by comparison.

\begin{tabular}{lcc}
\hline & $\begin{array}{c}\text { SBF } \\
(\mathbf{m m o l} / \mathbf{L})\end{array}$ & $\begin{array}{c}\text { Blood Plasma } \\
(\mathbf{m m o l} / \mathbf{L})\end{array}$ \\
\hline $\mathrm{Na}^{+}$ & 142.0 & 142.0 \\
$\mathrm{~K}^{+}$ & 5.0 & 5.0 \\
$\mathrm{Mg}^{2+}$ & 1.5 & 1.5 \\
$\mathrm{Ca}^{2+}$ & 2.5 & 2.5 \\
$\mathrm{Cl}^{-}$ & 148.8 & 103.0 \\
$\mathrm{H}_{2} \mathrm{PO}_{4}^{-}$ & 1.0 & 1.0 \\
$\mathrm{SO}_{4}{ }^{2-}$ & 0.5 & 0.5 \\
$\mathrm{HCO}_{3}{ }^{-}$ & 4.2 & 27.0 \\
\hline
\end{tabular}

The corrosion/dissolution testing protocol involved the immersion of samples $(\mathrm{CaP}$ coated and pristine $\mathrm{Mg}$ alloy controls) into $15 \mathrm{~mL}$ of the $\mathrm{SBF}$ solution in sterile containers which were then stored in an incubator at $37.5^{\circ} \mathrm{C}$ under normal atmospheric conditions for a period of 14 days. All $15 \mathrm{~mL}$ of the solution was replaced daily to mimic fluid exchange within the body. Samples were characterised at day 0 and day 14 for an individual sample size of $n=5$.

To calculate corrosion rate of the samples, by-products were removed post-immersion testing according to ASTM G01-03, "Standard practice for preparing, cleaning and evaluating corrosion test specimens" [45]. Corrosion rate was calculated in mm/year (mmpy) following the standardised formula given in the equation below, which assumes uniform sample corrosion:

$$
\text { Corrosion Rate }(\mathrm{CR})=\frac{K W}{A T D} \quad \text { Eq. } 1
$$


where $\mathrm{K}$ is a constant of value $8.76 \times 10^{4}, \mathrm{~W}$ is the mass loss $(\mathrm{g}), \mathrm{A}$ is the surface area $\left(\mathrm{cm}^{2}\right)$, $\mathrm{T}$ is the exposure time (h) and $\mathrm{D}$ is the density of the material $\left(\mathrm{g} / \mathrm{cm}^{3}\right)$ [46]. For each sample (before and after immersion in SBF), surface area and volume were obtained from Microcomputed Tomography ( $\mu \mathrm{CT})$ analysis and density was calculated from the original and residual masses measured using precision gravimetric analysis (Radwag, Poland 4Y precision scales, grams to 6 decimal places).

\subsection{Characterisation}

Optical microscopy was conducted using a 5-megapixel benchtop optical microscope (Aven Tools, USA), with samples imaged at the same nominal working)distance. The image calibration scales at this fixed working distance were then used to apply scale bars using the ImageJ software (NIH, USA).

$\mu \mathrm{CT}$ analysis was conducted using a SkyScan 1275 (Bruker, Germany), at an operating voltage of $40 \mathrm{kV}$ and current of $250 \mu \mathrm{A}$ with at a voxel size of $10 \mu \mathrm{m}$. Rotational images were reconstructed into slices using the instruments proprietary NRecon software. Reconstructed slices were set at a threshold capable of identifying the underlying material before bitwise operations were performed to calculate sample surface area and volume. All scans were reconstructed using the same reconstruction and threshold settings to ensure an accurate comparison.

X-ray Photoelectron Spectroscopy (XPS) was performed on an Axis Ultra DLD Spectrometer (Kratos, UK). Spectra were attained using monochromated Al Ka X-rays (hv = 1486.6 electron volts $(\mathrm{eV}))$ operating at anode conditions of $15 \mathrm{kV}$ and $10 \mathrm{~mA}(150 \mathrm{~W})$. During analysis, a hybrid lens mode was used (electrostatic and magnetic) with a $300 \mu \mathrm{m} \mathrm{x}$ $700 \mu \mathrm{m}$ analysis area, and a take-off angle (TOA) of $90^{\circ}$ with respect to the sample surface. Wide energy survey scans (WESS) were collected across the $0-1200 \mathrm{eV}$ binding energy 
(BE) range at a hemispherical analyser pass energy of $160 \mathrm{eV}$. Subsequent high-resolution spectra of the $\mathrm{O} 1 \mathrm{~s}, \mathrm{C} 1 \mathrm{~s}, \mathrm{Mg} 1 \mathrm{~s}, \mathrm{Ca} 2 \mathrm{p}$ and $\mathrm{P} 2 \mathrm{p}$ regions were collected at a pass energy of 20 $\mathrm{eV}$. An integrated charge neutraliser system operating with a filament current of $1.95 \mathrm{~A}$ and a charge balance between $3.3 \mathrm{~V}-3.6 \mathrm{~V}$ was used for all samples. Charging effects on the BE positions were further adjusted by setting the lowest $\mathrm{BE}$ component for the $\mathrm{C} 1 \mathrm{~s}$ spectral envelope to $284.8 \mathrm{eV}$ which is commonly accepted as adventitious carbon surface contamination. Three measurements were analyse per sample, with a linear background subtracted from each XPS spectra. The peak area of the most intense spectral lines for each elemental species was used to determine the percentage atomic concentration. Peak fitting of high-resolution spectra was carried out using CasaXPS (Casa Software Ltd.) software.

Scanning Electron Microscopy (SEM) with Energy Dispersive X-ray (EDX) analysis was performed using a Hitachi SU5000 field emission instrument (Hitachi, Japan) equipped with an X-max 80 silicon drift detector (Oxford Instruments, UK). Images were obtained using an accelerating voltage of $5 \mathrm{KeV}$ to generate a beam spot size of $50 \mathrm{~nm}$ at a relatively low magnification of $\mathrm{x} 1000$ in order to allow for analysis of a larger surface area. EDX maps were then obtained for each SEM image at a resolution of 1024 x 1024 pixels with an average of 5 frames for each map. These map datasets were used to determine the atomic percentage chemical composition and calculate the $\mathrm{Ca} / \mathrm{P}$ ratio for each sample.

Time-of-Flight Secondary Ion Mass Spectrometry (ToF-SIMS) data was obtained using a ToF-SIMS 5 instrument (IONTOF GmbH, Germany) equipped with a Bismuth (Bi) liquid metal ion gun. The primary ion species used was $\mathrm{Bi}^{1+}$ at a beam energy of $25 \mathrm{keV}$. Analysis was performed in the positive polarity over an area of 500 x $500 \mu \mathrm{m}$ to generate $1024 \times 1024$ pixels per ion image at a target current of $1 \mu \mathrm{A}$. Data sets were collected over 10 scans for each area imaged at a cycle time of $100 \mu$ s to allow for analysis of the appropriate mass range at a suitable resolution. Depth profiling was performed using a $\mathrm{Cs}^{+}$secondary ion beam 
operating at an energy of $10 \mathrm{keV}$ which was rastered over the area for $20 \mathrm{~s}$ intervals using a non-interlaced sputtering process between the subsequent analysis collection frames. Samples were depth profiled for a total time of $14400 \mathrm{~s}$. Coating thickness was obtained from the ToFSIMS data by determining the depth sputtering rate via measurement of crater depth at various time points using a DektakXT stylus profilometer (Bruker, Germany). Determination of the sputter time required to reach the crossover point between $\mathrm{Ca}^{+}$and $\mathrm{Mg}^{+}$ions then allowed for calculation of the coating thickness using these sputter rates correlated to the profilometry

data. 


\section{Results}

\subsection{RF Magnetron Sputter Deposited CaP Coatings on Magnesium Alloys}

Scanning electron micrographs of RF magnetron sputter deposited $\mathrm{CaP}$ coatings on polished AZ31 alloy substrates are shown in Figure 1. It is clear that striations created on the alloy during polishing are seen in the images acquired for the $\sim 70 \mathrm{~nm}$ and $\sim 210 \mathrm{~nm}$ thick coatings. There is evidence that the thicker coating is able to slightly in-fill this pronounced striation topography of the underlying substrate, Figure1c.
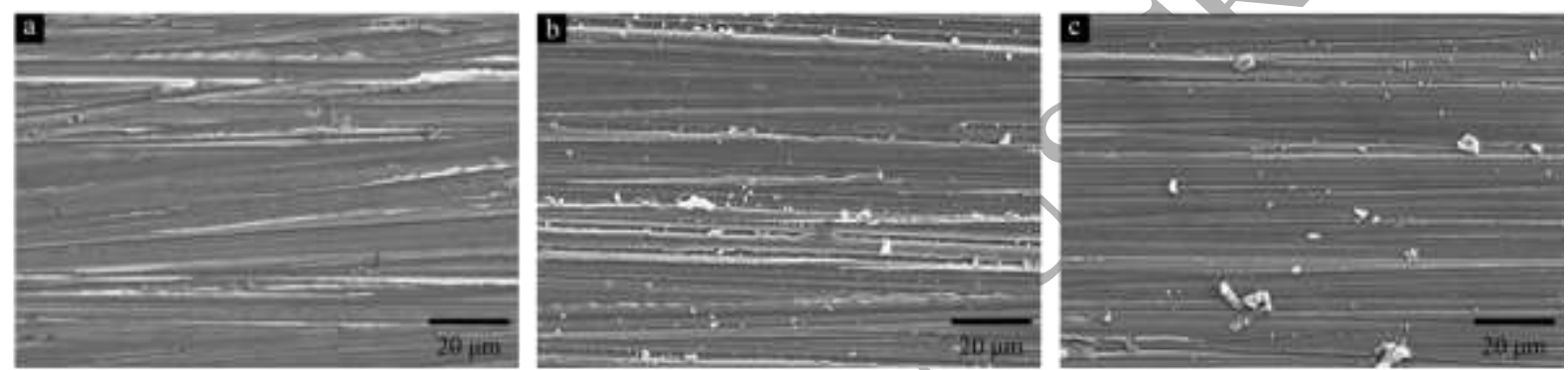

Figure 1 Scanning electron micrographs of p1200 polished AZ31 a) un-coated b) 70 nm CaP coating c) $\sim 210 \mathrm{~nm} \mathrm{CaP}$ coating.

EDX analysis carried out in tandem with the SEM imaging, highlights the expected presence of $\mathrm{Ca}$ and $\mathrm{P}$ in the sputter coated layer. The associated quantitative data, presented as percentage atomic concentration (at.\%) for each element, is provided in Table 3 and the associated chemical maps are shown in Figure 2, both of which confirm the difference in the $\mathrm{CaP}$ coating thickness. The accelerating voltage used was $5 \mathrm{kV}$, at this energy there is an approximated penetration depth of $354 \mathrm{~nm}$ for $\mathrm{CaP}$ [47], using an assumed density of approx. $3 \mathrm{~g} / \mathrm{cm}^{3}$ [48]. The data in Table 3 confirms we have achieved coatings of varying thickness as the underlying magnesium is less detectable in the $\sim 70 \mathrm{~nm}$ coated samples and almost undetectable in the $\sim 210 \mathrm{~nm}$ coated samples. Coated samples also exhibit a reduction in elemental carbon and $\mathrm{Ca} / \mathrm{P}$ ratios of 2.39 for $\sim 70 \mathrm{~nm}$ coated and 1.72 for $\sim 210 \mathrm{~nm}$ coated. 


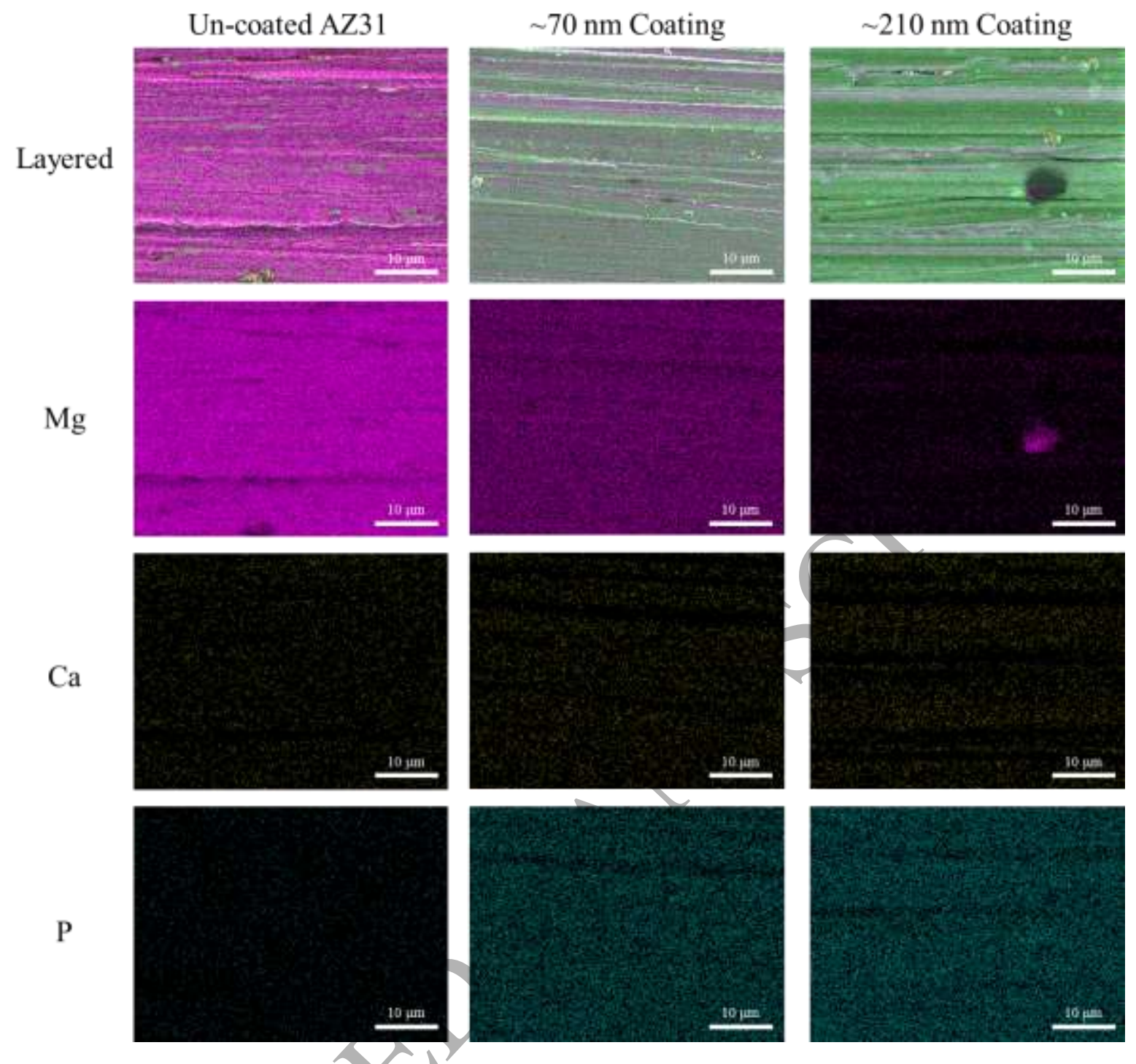

Figure 2 EDX chemical maps of un-coated, $70 \mathrm{~nm}$ and $\sim 210 \mathrm{~nm} \mathrm{CaP}$ coated AZ31with the corresponding colour designations: $\mathrm{Mg}$ - purple; $\mathrm{Ca}$ - yellow; $\mathrm{P}$ - blue. (PLEASE PUBLISH THIS FIGURE IN COLOUR)

Table 3 EDX quantitative elemental data reported as atomic $\%$ for un-coated AZ31, 70nm $\mathrm{CaP}$ coating and $\sim 210 \mathrm{~nm} \mathrm{CaP}$ coating.

\begin{tabular}{c|c|c|c} 
Element & Uncoated (at.\%) & 70nm (at.\%) & 210nm (at.\%) \\
\hline $\mathrm{Mg}$ & $79.4 \pm 2.40$ & $19.7 \pm 0.55$ & $1.20 \pm 0.12$ \\
$\mathrm{O}$ & $4.93 \pm 1.20$ & $39.1 \pm 0.45$ & $52.9 \pm 0.96$ \\
$\mathrm{Ca}$ & $0.13 \pm 0.15$ & $25.7 \pm 0.10$ & $26.0 \pm 0.67$ \\
$\mathrm{P}$ & $0.00 \pm 0.00$ & $10.8 \pm 0.12$ & $15.1 \pm 0.15$ \\
$\mathrm{C}$ & $13.7 \pm 0.63$ & $4.10 \pm 0.12$ & $4.70 \pm 0.25$ \\
$\mathrm{Al}$ & $2.36 \pm 0.28$ & $0.00 \pm 0.00$ & $0.00 \pm 0.00$ \\
$\mathrm{Ca} / \mathrm{P}$ Ratio & $0.00 \pm 0.00$ & $2.39 \pm 0.02$ & $1.72 \pm 0.03$
\end{tabular}


XPS high resolution scans of $\mathrm{Mg} 1 \mathrm{~s}, \mathrm{Ca} 2 \mathrm{p}$ and $\mathrm{P} 2 \mathrm{p}$ plots for polished un-coated AZ31 alloy and $\sim 70 \mathrm{~nm}$ and $\sim 210 \mathrm{~nm}$ CaP coatings thereon are shown in Figure 3, with proposed peak assignment binding energies in Table 4. As expected, the spectra for the un-coated AZ31 surface exhibits a strong Mg1s peak. The features in the Ca2p scan region are attributed to magnesium $\mathrm{x}$-ray induced Auger (secondary electron) lines with this interpretation confirmed by the lack of any peaks in the P2p high energy spectrum. The corresponding spectra for the CaP coated alloy surfaces show characteristic Ca2p and P2p doublet peaks in the relevant spectral regions. In the case of both the $\sim 70 \mathrm{~nm}$ and $\sim 210 \mathrm{~nm}$ thick coatings, no $\mathrm{Mg} 1 \mathrm{~s}$ peak is detected.
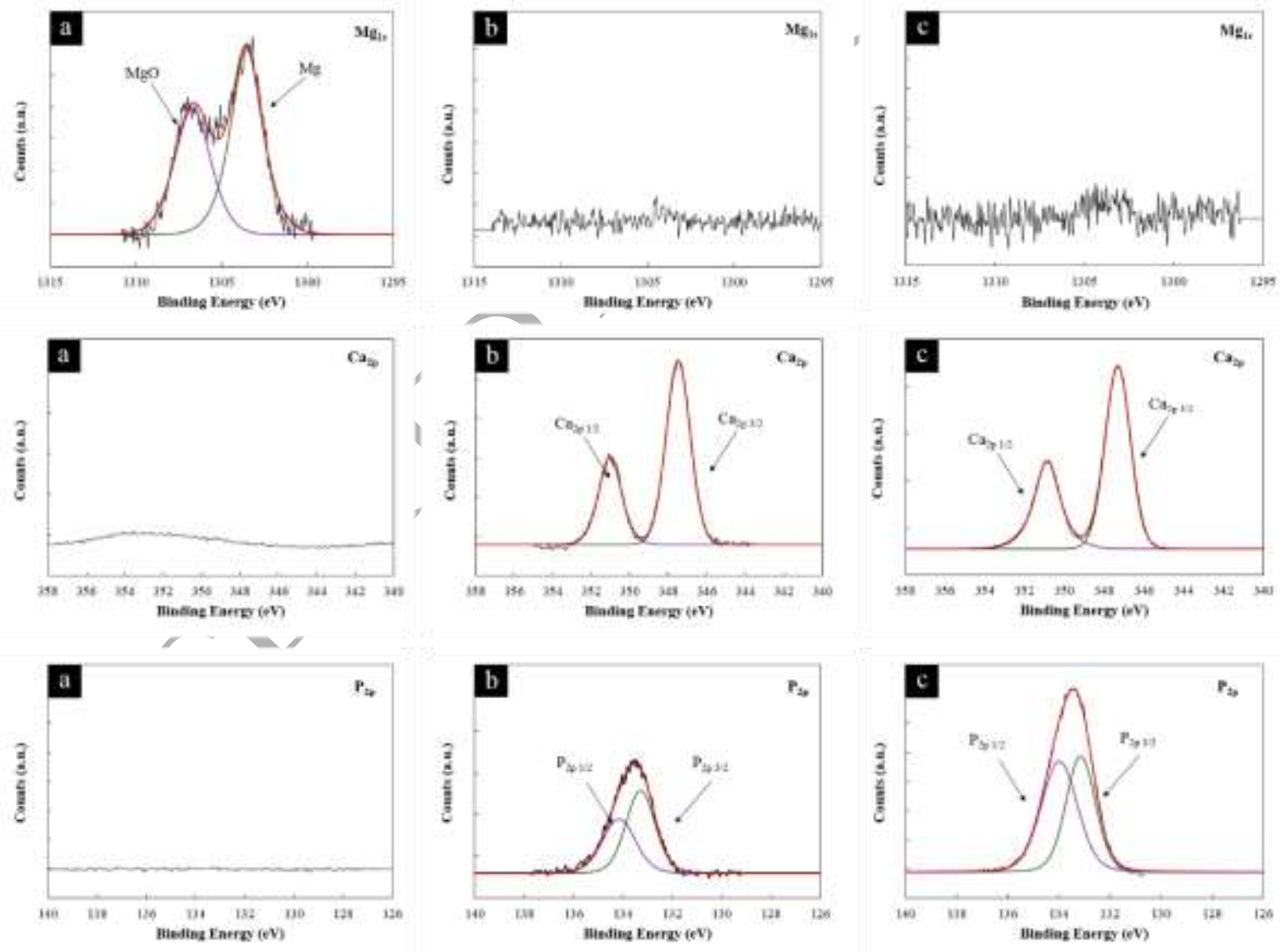

Figure 3 XPS high-resolution scans of Mg1s, Ca2p and P2p for a) un-coated b) $70 \mathrm{~nm} \mathrm{CaP}$ AZ31 and c) $210 \mathrm{~nm}$ CaP coated AZ31. 
Table 4 XPS binding energies (eV) of the proposed assignments for $\mathrm{Mg} 1 \mathrm{~s}, \mathrm{Ca} 2 \mathrm{p}$ and P2p

\begin{tabular}{c|c|c|c} 
Element & Un-coated & -70nm & 210nm \\
\hline $\mathrm{Mg}$ & 1303.55 & - & - \\
$\mathrm{MgO}$ & 1306.71 & - & - \\
$\mathrm{Ca}_{2 \mathrm{p} 3 / 2}$ & - & 351.02 & 350.87 \\
$\mathrm{Ca}_{2 \mathrm{p} 1 / 2}$ & - & 347.49 & 347.32 \\
$\mathrm{P}_{2 \mathrm{p} 3 / 2}$ & - & 133.29 & 133.14 \\
$\mathrm{P}_{2 \mathrm{p} 1 / 2}$ & - & 134.16 & 133.98
\end{tabular}

Time-of-Flight Secondary Ion Mass Spectrometry (ToF-SIMS) was used to further determine the nature of the chemistry of the $\mathrm{CaP}$ sputter deposited coatings and the interface that it makes with the polished AZ31 alloy surface.

Figure 4a) and b) provide depth profiling data as rendered $x-y$ plots and intensity versus sputter time plots for the $\sim 70 \mathrm{~nm}$ and $\sim 210 \mathrm{~nm}$ thick coatings, respectively. The $\mathrm{CaOH}^{+}$ion at mass $(\mathrm{m} / \mathrm{z}) 56.96$ amu is used to identify the CaP coating while the $\mathrm{Mg}^{+}$ion at mass $(\mathrm{m} / \mathrm{z})$ $23.98 \mathrm{amu}$ is used for the AZ31 alloy substrate. ToF-SIMS ion maps captured in positive polarity mode using the ion counts for the $\mathrm{CaOH}^{+}, \mathrm{Ca}^{+}$(ion at mass (m/z) $40.08 \mathrm{amu}$ ) and $\mathrm{Mg}^{+}$ions for the $\sim 210 \mathrm{~nm}$ thick coating are provided in

Figure 4c). The striations created on the AZ31 alloy during polishing can again be clearly seen in the total ion count, $\mathrm{CaOH}^{+}$and $\mathrm{Ca}^{+}$ion images for these coatings. 


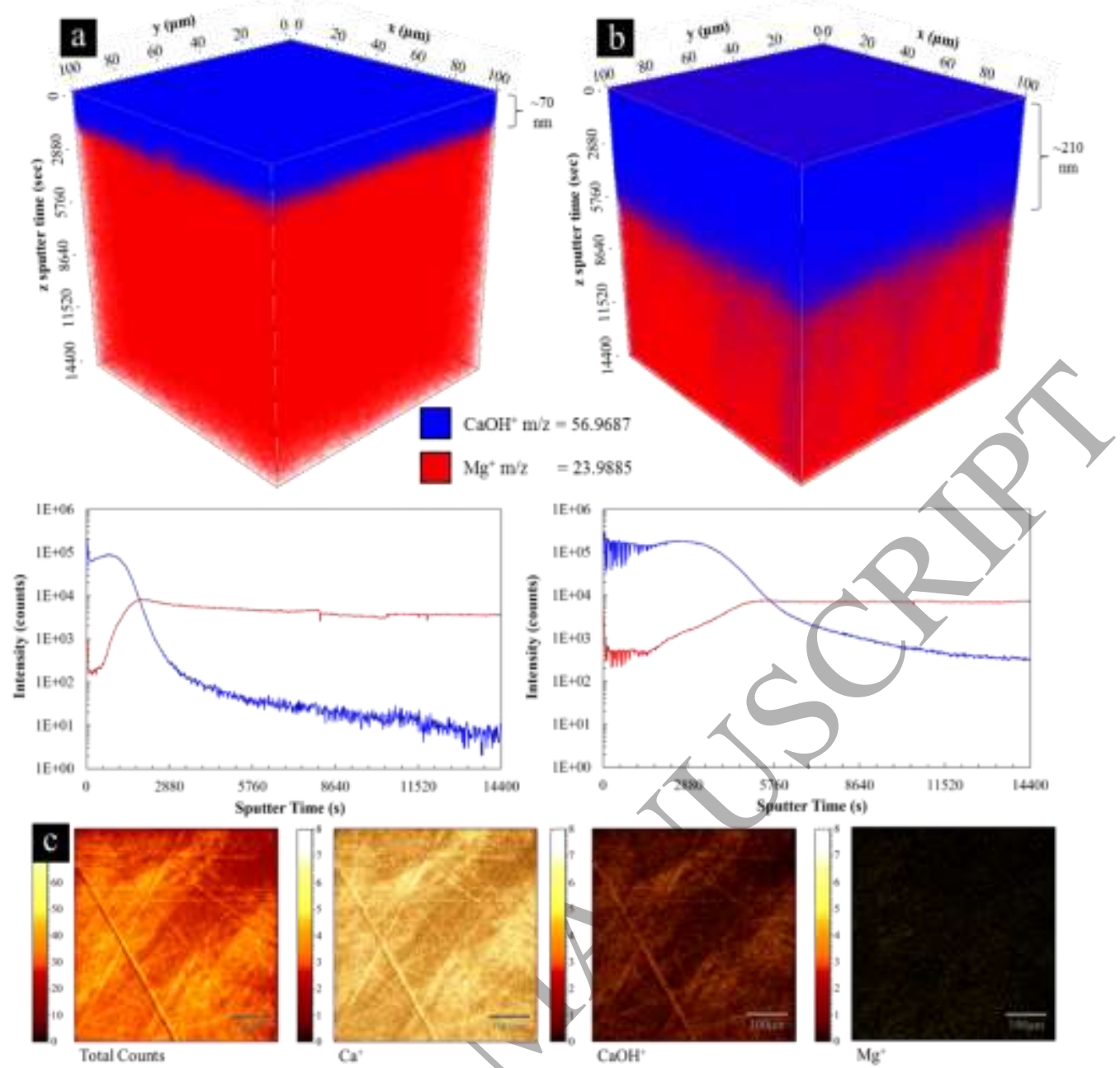

Figure 4 ToF-SIMS depth profiles of a) $\sim 70 \mathrm{~nm} \mathrm{CaP}$ coated AZ31 and b) $\sim 210 \mathrm{~nm} \mathrm{CaP}$ coated AZ31. c) ToF-SIMS positive polarity ion mapping of $\sim 210 \mathrm{~nm} \mathrm{CaP}$ coated AZ31, highlighting the $\mathrm{Ca}^{+}, \mathrm{CaOH}^{+}$and $\mathrm{Mg}^{+}$peaks, the colour intensity of the ion maps and associated scales represents counts of ions detected. (PLEASE PUBLISH THIS FIGURE IN COLOUR)

\subsection{Corrosion/Dissolution Testing of RF Magnetron Sputter Deposited CaP Coatings on Magnesium Alloys}

Optical micrographs of RF magnetron sputter deposited CaP coatings on polished AZ31 alloy before and after exposure to SBF for 14 days are provided in Figure 5. No visible corrosion can be seen in any of the samples pre-immersion, with the $\mathrm{CaP}$ coated samples exhibiting a slight pearlescent hue. Visible corrosion can be seen in the post-immersion images, particularly for the un-coated and $70 \mathrm{~nm}$ CaP coated samples. 


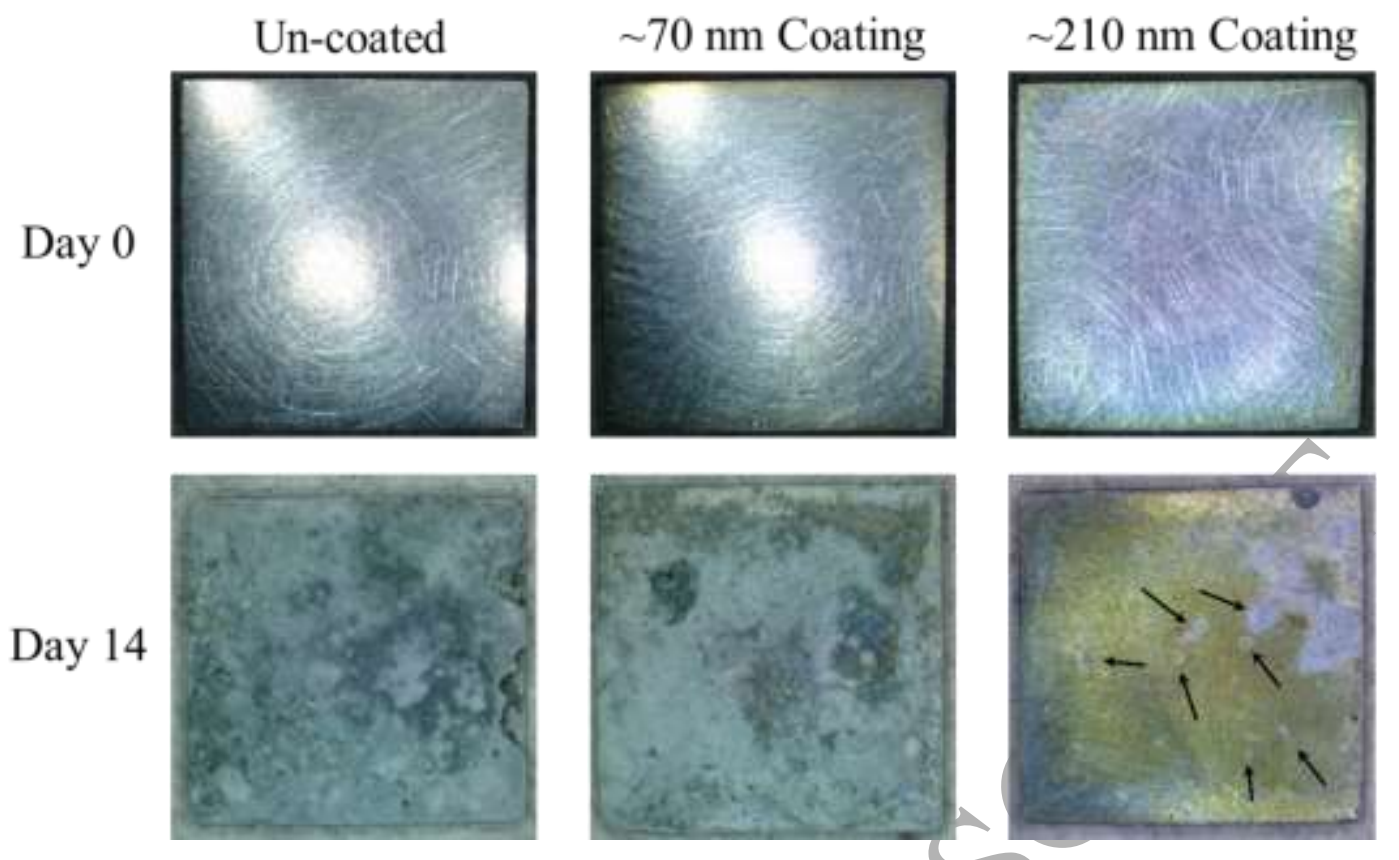

Figure 5 Optical images of AZ31 coupons pre- and post- exposure to SBF for 14 days. Arrows indicate areas where coating has been dissoluted and significant visible corrosion can be seen on the underlying AZ31 coupon. (PLEASE PUBLISH THIS FIGURE IN COLOUR)

SEM examination of the $\sim 70 \mathrm{~nm}$ and $\sim 210 \mathrm{~nm}$ thick CaP coated AZ31 alloy samples postimmersion testing in SBF shows that a significant build-up of corrosion products has occurred in both cases in the 14 day period, as shown in Figure 6. 

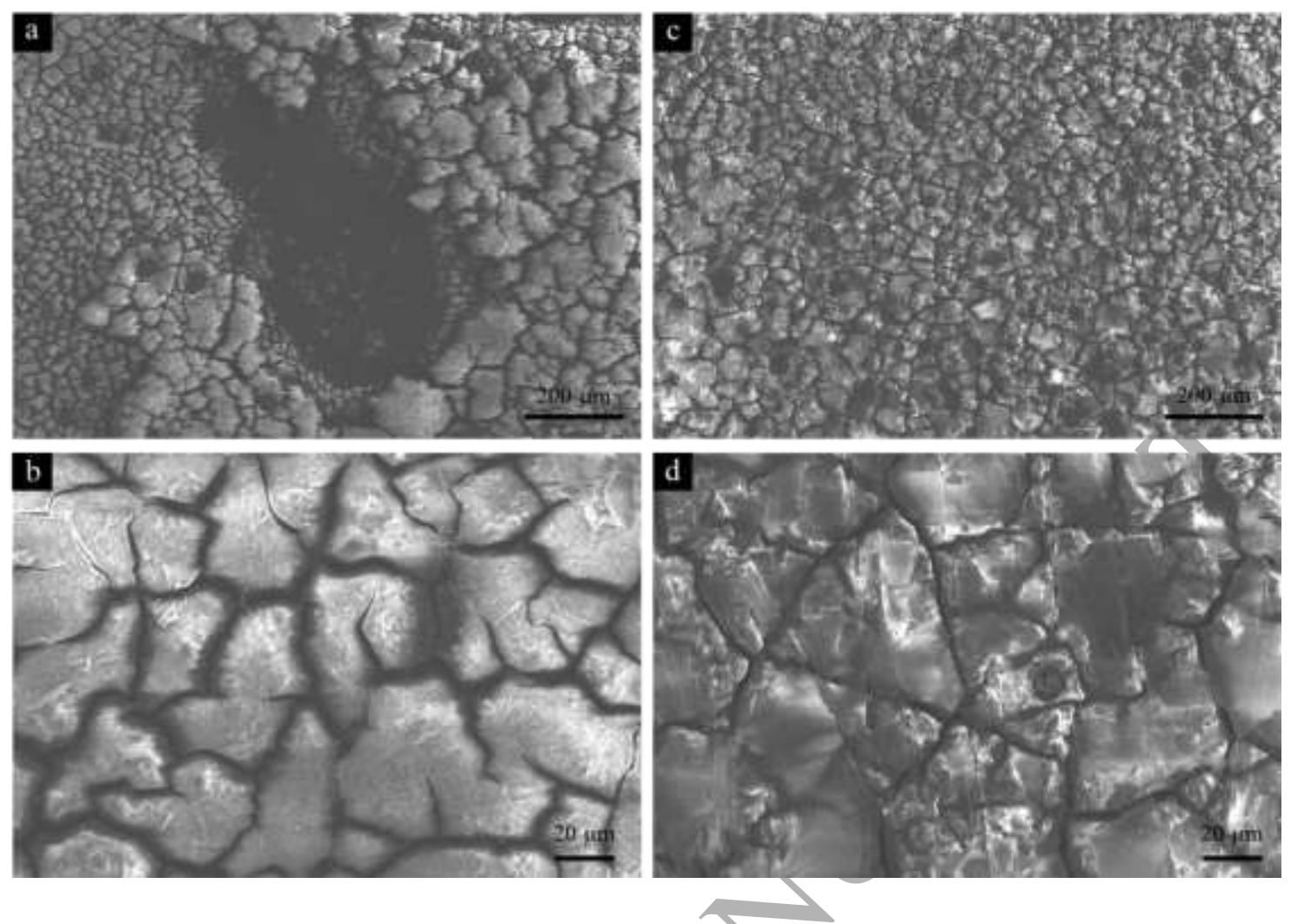

Figure 6 Scanning electron micrographs of $\mathrm{CaP}$ coated AZ31 coupons post-immersion in SBF for 14 days a) $\sim 70 \mathrm{~nm} \times 100 \mathrm{~b}) \sim 70 \mathrm{~nm} \times 600 \mathrm{c}$ ) $\sim 210 \mathrm{~nm} \times 100 \mathrm{~d}$ ) $\sim 210 \mathrm{~nm}$ coated 6600 .

EDX analysis of the corrosion products indicates a significant change in the chemical composition between the two samples post-immersion, as shown by the data provided in Table 5. The thicker of the two CaP coatings $(\sim 210 \mathrm{~nm})$ clearly exhibits a greater $\mathrm{Ca}$ and $\mathrm{P}$ atomic concentration post-immersion and hence a higher $\mathrm{Ca} / \mathrm{P}$ ratio than the thinner coating $(\sim 70 \mathrm{~nm})$. There is a significant increase in oxygen at.\% as thick oxide layers have formed on the surface of the samples. The at.\% of magnesium is higher on the $\sim 70 \mathrm{~nm}$ coated samples than the $\sim 210 \mathrm{~nm}$ coated samples, due to the presence of a greater remaining coating thickness on the 210 samples and the penetrating depth of a $5 \mathrm{kV}$ accelerating voltage electron beam [47]. 
Table 5 Atomic percentage composition of CaP coated AZ31 samples post-immersion in SBF for 14 days, obtained via EDX analysis.

\begin{tabular}{c|c|c} 
Element & 70nm (at.\%) & 210nm (at.\%) \\
\hline $\mathrm{Mg}$ & $9.00 \pm 0.26$ & $2.37 \pm 0.15$ \\
$\mathrm{O}$ & $67.2 \pm 0.55$ & $58.6 \pm 2.11$ \\
$\mathrm{Ca}$ & $3.73 \pm 0.06$ & $9.53 \pm 0.55$ \\
$\mathrm{P}$ & $5.80 \pm 0.10$ & $8.00 \pm 0.26$ \\
$\mathrm{C}$ & $10.6 \pm 0.46$ & $19.5 \pm 3.05$ \\
$\mathrm{Al}$ & $2.97 \pm 0.15$ & $1.30 \pm 0.17$ \\
$\mathrm{C} / \mathrm{P}$ Ratio & $0.64 \pm 0.01$ & $1.19 \pm 0.03$
\end{tabular}

Rendered volumetric $\mu \mathrm{CT}$ images for the un-coated AZ31 alloy and the $\sim 70 \mathrm{~nm}$ and 210 $\mathrm{nm}$ thick CaP coatings thereon post-immersion in SBF for 14 days are provided in Figure 7a). The un-coated control alloy clearly exhibits a distinctive area of volume loss and significant pitting across much of the rendered surface. By comparison, the $\sim 70 \mathrm{~nm}$ coated samples has one relatively small area of total volume loss and less pitting. Inspection of the reconstructed volume of $\sim 210 \mathrm{~nm}$ coated alloy samples shows that whereas corrosion has begun to occur, as evidenced by several areas of pitting, no areas of complete loss are observed.

Using voxel counting software to undertake bitwise calculations volume and surface area of samples were determined and volume loss of the samples calculated, as shown in Figures 7b). Pre-degradation the samples exhibited a volume of $92 \pm 1.14 \mathrm{~mm}^{3}$ and surface area of $224 \pm 2.96 \mathrm{~mm}^{2}$. At 14 days the uncoated AZ31 control exhibited a volume loss of $5.89 \pm$ $3.15 \mathrm{~mm}^{3}$, while the samples with $\sim 70 \mathrm{~nm}$ and $210 \mathrm{~nm} \mathrm{CaP}$ coatings had volume losses of $3.42 \pm 0.48 \mathrm{~mm}^{3}$ and $0.30 \pm 0.28 \mathrm{~mm}^{3}$, respectively. The extent of surface area increase in a sample can also be linked to the extent of corrosion. At 14 days uncoated AZ31 samples exhibited an increase in surface area of $19.15 \pm 8.15 \mathrm{~mm}^{2}$, with $\sim 70 \mathrm{~nm}$ and $210 \mathrm{~nm} \mathrm{CaP}$ coated samples exhibiting an increase of $9.06 \pm 4.22 \mathrm{~mm}^{2}$ and $4.53 \pm 5.47 \mathrm{~mm}^{2}$ respectively. This data confirms that the thicker $\mathrm{CaP}$ coating is able to significantly delay the corrosion of the underlying alloy. 


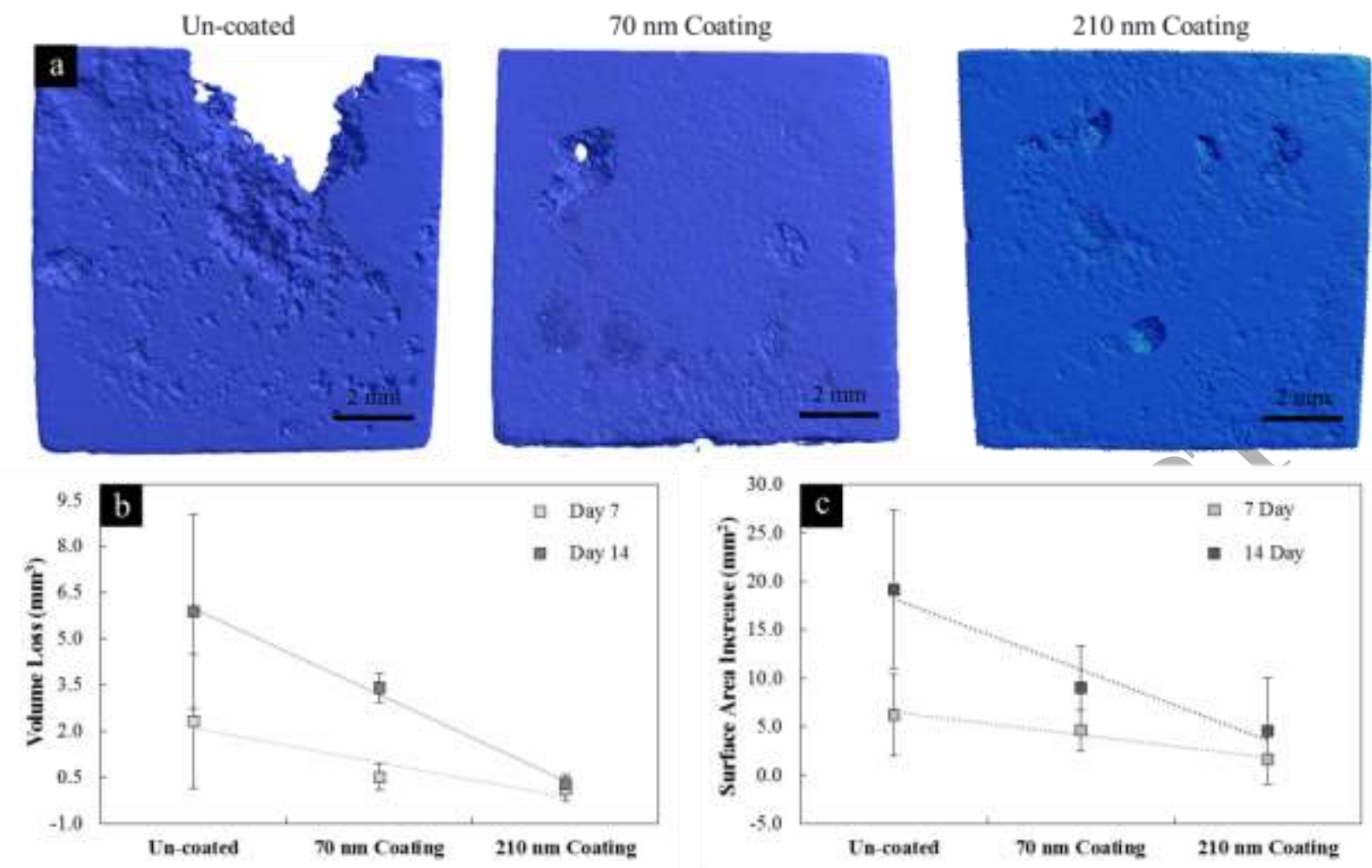

Figure 7 Volumetric $\mu \mathrm{CT}$ analysis of un-coated AZ31 and CaP coated samples postimmersion to SBF for 14 days: a) volumetric reconstructions detailing the visual extent of volume loss across samples; b) mean volume loss \pm SD and c) mean surface area increase \pm SD. (PLEASE PUBLISH THIS FIGURE IN COLOUR)

Gravimetric measurements obtained from samples post-immersion using precision scales (values in grams to 6 decimal points) were used to calculate corrosion rates for the $\sim 70 \mathrm{~nm}$ and $210 \mathrm{~nm} \mathrm{CaP}$ coated samples and compared to the uncoated control with the data shown in

Figure 8 . A statistically significant reduction in corrosion rate was exhibited by both of the coated samples with the thinner $\sim 70 \mathrm{~nm} \mathrm{CaP}$ coating giving a value of $1.57 \pm 0.09 \mathrm{mmpy}$ compared to uncoated AZ31which exhibited a corrosion rate of $1.74 \pm 0.06 \mathrm{mmpy}(\mathrm{p}<0.05)$. A statistically significantly greater decrease in corrosion rate $(\mathrm{p}<0.001)$ was exhibited by $\sim 210 \mathrm{~nm}$ thick CaP coating which had a value of $1.01 \pm 0.07$ mmpy. 


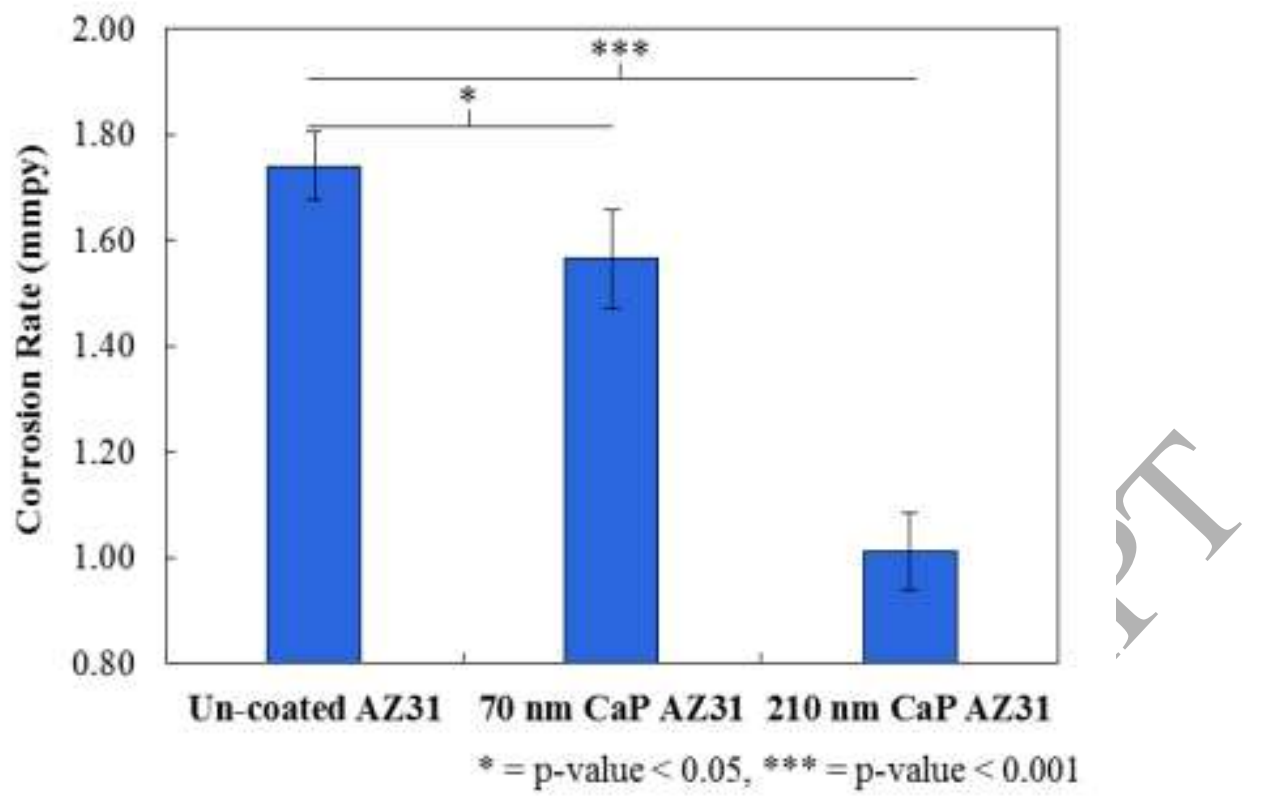

Figure 8 Corrosion rates (mmpy) for uncoated and $\sim 70 \mathrm{~nm}$ and $\sim 210 \mathrm{~nm} \mathrm{CaP}$ coated AZ31 samples post-immersion in SBF for 14 days calculated after removal of corrosion products as per ASTM G01-03. 


\section{Discussion}

\subsection{Physical and Chemical Properties of CaP Coatings on AZ31}

Polishing of the AZ31 alloy surface results in the formation of striations that can be clearly seen in the SEM images of the prepared samples. Sputter deposition of CaP onto this surface results in the creation of a conformal coating on top of these features that is thin but homogeneous, i.e. there are no features suggestive of a $\mathrm{CaP}$ microstructure perse.

The EDX analysis was conducted at $5 \mathrm{kV}$ to confine the EDX information depth to the $\mathrm{CaP}$ coating while still maintaining acceptable atomic sensitivity. Analysis indicates that there is a trace amount of $\mathrm{Ca}$ present in the native alloy control. As expected, the at.\% concentration of $\mathrm{Ca}$ and $\mathrm{P}$ increases significantly after coating of the alloy surface. However, the amount of $\mathrm{Ca}$ detected for the $\sim 210 \mathrm{~nm}$ coating is found to be the same as that for the 70 $\mathrm{nm}$ coating while the corresponding at. $\% \mathrm{P}$ value increases only slightly for the thicker $\mathrm{CaP}$ layer. This is deemed to be a consequence of the nature of the underlying substrate surface roughness and the effect this has on the coherency of the coating thickness across the striations which then has an effect on the accuracy of the EDX measurements for the thicker $\mathrm{CaP}$ coating. There is potentially some slight contamination of the samples with carbon, from polishing with silicon carbide abrasive, which is observed on the uncoated samples, subsequently removed by the plasma during the initial stages of deposition. For the $\sim 210 \mathrm{~nm}$ coating the $\mathrm{Ca} / \mathrm{P}$ ratio is close to stoichiometric hydroxyapatite, for the thinner coating it is significantly higher. This atypical value may be an artefact of the relatively large information depth at an accelerating voltage of $5 \mathrm{kV}$ [47] and the EDX quantification algorithm which assumes bulk compositions. The effect of the penetrating electron beam can be seen in the varying magnesium at. $\%$ of the two coated samples, indicating that for the $\sim 70 \mathrm{~nm}$ coated samples more information is being picked up from the underlying alloy. This analysis 
corroborates our ToF-SIMS depth profiling confirming a significant difference in coating thickness between the two groups of samples.

XPS analysis shows that both the $\sim 70 \mathrm{~nm}$ and $\sim 210 \mathrm{~nm}$ thick CaP coatings suppress the detection of the underlying magnesium alloy $(\mathrm{Mg} 1 \mathrm{~s})$ signal. This result with the SEM-EDX analysis, this suggests that the $\mathrm{CaP}$ layer does indeed conform to the striations created on the alloy surface during polishing to form a coherent layer. This is consistent with previous reports in the literature which show RF magnetron sputtered coatings are dense and homogeneous [49]. Attempts to measure the $\mathrm{Ca} / \mathrm{P}$ ratios on the $\mathrm{CaP}$ surfaces úsing XPS were unsuccessful as the surface roughness of the underlying alloy causes shadowing effects that distort the relative numbers of the $\mathrm{Ca} 2 \mathrm{p}$ and $\mathrm{P} 2 \mathrm{p}$ photoelectrons arriving at the detection measurement system.

ToF-SIMS depth profiling data confirms that the difference in the thickness of the two coatings is as expected from the operational conditions used during sputtering. Again, these data suggest that a coherent and conformal CaP layer is deposited onto the polished AZ31 in both cases, which is consistent with the findings from both the XPS and EDX results. Importantly, the interface between the $\mathrm{CaP}$ coating and the magnesium alloy is relatively sharp with no evidence of significant intermixing having occurred as a consequence deposition. The small amount of $\mathrm{CaOH}^{+}$ions that seem to be present within the underlying magnesium alloy in the case of the $\sim 210 \mathrm{~nm}$ CaP coated samples (Figure $4 \mathrm{~b}$ ) are deemed to be due to atomic mixing caused by the experimental secondary ion depth profile beam $\left(\mathrm{Cs}^{+}\right)$ rather than diffusion of $\mathrm{Ca}$ and $\mathrm{P}$ into the magnesium alloy during the coating process. The positive polarity ion maps (Figure 4c) also confirm the coherency and conformal nature of the coating as indicated by the strong counts for $\mathrm{Ca}^{+}$and $\mathrm{CaOH}^{+}$ions and relatively weak counts for $\mathrm{Mg}^{+}$ions. 


\subsection{Static Solution Immersion Corrosion Testing}

Optical imaging (Figure 5) clearly indicates that the uncoated AZ31 samples undergo corrosion and subsequent degradation after the 14 days immersion in SBF, with large quantities of the coupon samples being lost to solution. By comparison, the presence of a $\sim 70$ $\mathrm{nm} \mathrm{CaP}$ coating on the alloys surface appears to help to delay the initiation of the corrosion process, with visually less corrosion evident for the corresponding underlying AZ31 coupon post-immersion. A thicker CaP coating $(\sim 210 \mathrm{~nm})$ exhibits a more significant reduction in the corrosion that normally occurs to the underlying AZ31 coupon, with some of the coating appearing to be still present on the surface at the end of the 14-day experimental protocol used here. The corrosion in these samples only occurs in specific areas (as indicated by arrows on Figure 5) where the coating has dissolved over the 14-day immersion period to expose the underlying alloy.

EDX data of the CaP coated samples post-immersion and prior to removal of corrosion products shows a significant change in the elemental composition, comparing table 3 and 5, with an increase in $\mathrm{C}$ at. $\%$ and $\mathrm{O}$ at. $\%$. This can be attributed to precipitation of carbonates present in the SBF solution and potentially to the dissolution of the hydroxyapatite like $\mathrm{CaP}$ coating. The $\sim 70 \mathrm{~nm}$ coated samples exhibited a larger change in elemental composition than the $\sim 210 \mathrm{~nm}$ coated samples with an increase in oxygen, decrease in $\mathrm{Ca}$ at. $\%$ and $\mathrm{P}$ at. $\%$ and the appearance of an aluminium peak from the underlying alloy, Figure 5. The elemental composition of the $\sim 210 \mathrm{~nm}$ coated samples didn't change as drastically as the $\sim 70 \mathrm{~nm}$ samples due to the thicker coating delaying the onset of corrosion. This is confirmed by the smaller at.\% of magnesium, the higher at. $\%$ of $\mathrm{Ca}$ and $\mathrm{P}$ and the smaller aluminium peak appearance compared to the $\sim 70 \mathrm{~nm}$ coated samples. This information alongside the $\mu \mathrm{CT}$ and optical micrographs confirms the effectiveness of the $\sim 210 \mathrm{~nm} \mathrm{CaP}$ coating in delaying the onset of corrosion that would normally occur to the underlying AZ31 coupon. 
Volumetric reconstructions from the $\mu \mathrm{CT}$ analysis show the physical effects of the extensive corrosion and associated total volume loss that occurs for the un-coated AZ31 alloy. Coating the AZ31 with a $\sim 70 \mathrm{~nm}$ thick $\mathrm{CaP}$ coating causes a reduction in the corrosion rate as indicated by the nature and scale of the volume loss. Analysis of the $\sim 210 \mathrm{~nm}$ thick $\mathrm{CaP}$ coated samples shows a more significant reduction in the overall volume loss with areas of pitting present where the coating has dissolved. These data are consistent with the interpretation of the optical images, in that part of the coating remains intact after 14 days exposure to SBF, with significant corrosion only occurring in areas whereby coating has completely dissolved. Surface area measurements from the $\mu \mathrm{CT}$ rendered images (Figure 7c) further consolidate these findings, specifically that the $\sim 70 \mathrm{~nm} \mathrm{CaP}$ coated coupons exhibit larger increases in surface area when compared to that for the $210 \mathrm{~nm}$ samples postimmersion in SBF for 14 days. This indicates that corrosion has occurred to a significantly lesser extent in the case of the $\sim 210 \mathrm{~nm}$ CaP layer on the magnesium alloy.

Corrosion rate calculations show that these $\mathrm{CaP}$ coatings can indeed act as a partial barrier layer due to the difference in dissolution properties in aqueous solution at $37^{\circ} \mathrm{C}$ that results from varying $\mathrm{CaP}$ coating thickness. The onset of corrosion on and within the underlying AZ31 alloy is significantly delayed until the coating has been sufficiently dissolved away by the SBF solution. In this respect, the thicker $(\sim 210 \mathrm{~nm})$ coating simply requires a greater samplelength of time to dissolve away and so acts as corrosion barrier layer for longer.

Based on these results presented in this work, it is clear that RF magnetron sputter deposited CaP coatings are sufficiently dense and homogenous so as to act as a partial barrier layer in a manner that protects the AZ31 coupons from full exposure to the surrounding SBF solution. This dense partial barrier layer then dissolves over time in representative physiological media, exposing the underlying magnesium alloy and initiating corrosion. By altering the thickness of the $\mathrm{CaP}$ coating, corrosion of the underlying magnesium can be 
delayed further, therefore, it is speculated that this control of corrosion for a specified duration could be tailored via the deposition of a $\mathrm{CaP}$ coating of specific thickness. Moreover, previous studies have shown that this type of RF magnetron sputtered $\mathrm{CaP}$ thin films can enhance the response of human mesenchymal stem cells in vitro [33], meaning that the dissolving of the CaP coating can not only be used to potentially tailor the rate of corrosion of the underlying alloy but could also boost bone cell activity in the localised implant area.

\section{Conclusions}

Control of the corrosion that normally occurs in magnesium alloys with potential for use as resorbable orthopeadic implants by the use of bioactive $\mathrm{CaP}$ coatings has been investigated. RF magnetron sputtering from HA powder targets has been employed to create ultra-thin CaP coatings on AZ31 magnesium alloy substrates at two different thicknesses, $\sim 70 \mathrm{~nm}$ and $\sim 210 \mathrm{~nm}$. XPS and ToF-SIMS analysis have confirmed the composition and thickness of the $\mathrm{CaP}$ layers. The $\mathrm{Ca} / \mathrm{P}$ atomic ratio of the coatings is difficult to determine with XPS due to the substrate roughness but has determined by EDX to be 1.54. $\mu \mathrm{CT}$ analysis has been used to observe and measure the alloy volume loss for un-coated and $\mathrm{CaP}$ coated AZ31 after 14 days exposure to SBF. The control exhibited a volume loss of $5.89 \pm 3.15 \mathrm{~mm}^{3}$ while the presence of the $\sim 70 \mathrm{~nm} \mathrm{CaP}$ coating reduced this to $3.42 \pm 0.48 \mathrm{~mm}^{3}$ and the 210 $\mathrm{nm} \mathrm{CaP}$ coating even more so to $0.30 \pm 0.28 \mathrm{~mm}^{3}$. Hence, the thicker CaP coating is able to significantly delay the corrosion of the underlying alloy. The corresponding corrosion rates follow the same trend with the un-coated AZ31 returning a value of $1.74 \pm 0.06 \mathrm{mmpy}$, the $\sim 70 \mathrm{~nm} \mathrm{CaP}$ coating $1.57 \pm 0.09$ mmpy and the $\sim 210 \mathrm{~nm}$ thick $\mathrm{CaP}$ coating $1.01 \pm 0.07$ mmpy compared. Overall, the most statistically significant decrease in corrosion rate $(\mathrm{p}<$ 0.001) was exhibited by $\sim 210 \mathrm{~nm}$ thick $\mathrm{CaP}$ coating. These data confirm that $\mathrm{CaP}$ coating 
thickness can indeed control the rate of corrosion of magnesium alloys. In addition, the combination of magnesium alloy corrosion and $\mathrm{CaP}$ dissolution provides the potential for improved bioactivity by offering an attendant physiochemical environment with properties known to promote an osteoinductive response in vivo. The delivery of these significant benefits is the basis of on-going work in the area.

\section{Acknowledgements}

Funding of this work from the Department for the Economy (DfE), Northern Ireland for a US-Ireland Centre-to-Centre Partnership established in collaboration with North Carolina Agricultural and Technical State University, University of Pittsburgh, University of Cincinnati, Cincinnati Children's Hospital, and the National University Ireland, Galway (USI 111 ) is gratefully acknowledged.

\section{Declaration of Interest}

Declaration of Interest - None. 


\section{References}

[1] T. Hanawa, Overview of metals and applications, in: M.B.T.-M. for B.D. Niinomi (Ed.), Met. Biomed. Devices, Woodhead Publishing, 2010: pp. 3-24. doi:https://doi.org/10.1533/9781845699246.1.3.

[2] K. Strømsøe, Fracture fixation problems in osteoporosis, Injury. 35 (2004) 107-113. doi:https://doi.org/10.1016/j.injury.2003.08.019.

[3] P. V Giannoudis, E. Schneider, Principles of fixation of osteoporotic fractures, J. Bone Joint Surg. Br. 88-B (2006) 1272-1278. doi:10.1302/0301-620X.88B10.17683.

[4] P. Aspenberg, Silk, metal and bone: why take implants out?, Nat. Rev. Rheumatol. 10 (2014) 386. https://doi.org/10.1038/nrrheum.2014.57.

[5] G. Reith, V. Schmitz-Greven, K.O. Hensel, M.M. Schneider, T. Tinschmann, B. Bouillon, C. Probst, Metal implant removal: benefits and drawbacks - a patient survey, BMC Surg. 15 (2015) 96. doi:10.1186/s12893-015-0081-6.

[6] C. Campbell, K. Lin, Complications of Rigid Internal Fixation, Craniomaxillofacial Trauma Reconstr. 2 (2009) 041-047. doi:10,1055/s-0029-1202596.

[7] K. Wang, The use of titanium for medical applications in the USA, Mater. Sci. Eng. A. 213 (1996) 134-137. doi:https://doi.org/10.1016/0921-5093(96)10243-4.

[8] S.M. Perren, Evolution of the Internal Fixation of Long Bone Fractures, J. Bone Joint Surg. Br. 84-B (2002) 1093-1109.

http://openurl.ingenta.com/content/xref?genre=article\&issn=1938$6478 \&$ volume $=2008 \&$ issue $=15 \&$ spage $=1932$.

[9] D. Zhao, F. Witte, F. Lu, J. Wang, J. Li, L. Qin, Current status on clinical applications of magnesium-based orthopaedic implants: A review from clinical translational perspective, Biomaterials. 112 (2017) 287-302. doi:https://doi.org/10.1016/j.biomaterials.2016.10.017.

[10] F. Witte, V. Kaese, H. Haferkamp, E. Switzer, A. Meyer-Lindenberg, C.J. Wirth, H. Windhagen, In vivo corrosion of four magnesium alloys and the associated bone response, Biomaterials. 26 (2005) 3557-3563. doi:https://doi.org/10.1016/j.biomaterials.2004.09.049. 
[11] A. Chaya, S. Yoshizawa, K. Verdelis, N. Myers, B.J. Costello, D.-T. Chou, S. Pal, S. Maiti, P.N. Kumta, C. Sfeir, In vivo study of magnesium plate and screw degradation and bone fracture healing, Acta Biomater. 18 (2015) 262-269. doi:https://doi.org/10.1016/j.actbio.2015.02.010.

[12] S. Yoshizawa, A. Brown, A. Barchowsky, C. Sfeir, Magnesium ion stimulation of bone marrow stromal cells enhances osteogenic activity, simulating the effect of magnesium alloy degradation, Acta Biomater. 10 (2014) 2834-2842. doi:https://doi.org/10.1016/j.actbio.2014.02.002.

[13] A. Chaya, S. Yoshizawa, K. Verdelis, S. Noorani, B.J. Costello, C. Sfeir, Fracture Healing Using Degradable Magnesium Fixation Plates and Screws, J. Oral Maxillofac. Surg. 73 (2015) 295-305. doi:https://doi.org/10.1016/j.joms.2014.09.007.

[14] J.-W. Lee, H.-S. Han, K.-J. Han, J. Park, H. Jeon, M.-R. Ok, H.-K. Seok, J.-P. Ahn, K.E. Lee, D.-H. Lee, S.-J. Yang, S.-Y. Cho, P.-R. Cha, H. Kwon, T.-H. Nam, J.H. Lo Han, H.-J. Rho, K.-S. Lee, Y.-C. Kim, D. Mantovani, Long-term clinical study and multiscale analysis of in vivo biodegradation mechanism of $\mathrm{Mg}$ alloy, Proc. Natl. Acad. Sci. 113 (2016) 716-721. doi:10.1073/pnas.1518238113.

[15] G.-W. Mao, H.-B. Gong, Y. Wang, X. Li, R. Lv, J. Sun, W.-G. Bian, Special Biodegradable Fixation Device for Anterior Cruciate Ligament Reconstruction-Safety and Efficacy in a Beagle Model, ACS Biomater. Sci. Eng. 4 (2018) 3600-3609. doi:10.1021/acsbiomaterials.8b00426.

[16] F. Witte, N. Hort, C. Vogt, S. Cohen, K.U. Kainer, R. Willumeit, F. Feyerabend, Degradable biomaterials based on magnesium corrosion, Curr. Opin. Solid State Mater. Sci. 12(2008) 63-72. doi:10.1016/j.cossms.2009.04.001.

[17] E. Brooks, M. Ehrensberger, Bio-Corrosion of Magnesium Alloys for Orthopaedic Applications, J. Funct. Biomater. 8 (2017) 38. doi:10.3390/jfb8030038.

[18] Y.F. Zheng, X.N. Gu, F. Witte, Biodegradable metals, Mater. Sci. Eng. R Reports. 77 (2014) 1-34. doi:https://doi.org/10.1016/j.mser.2014.01.001.

[19] Z. Li, X. Gu, S. Lou, Y. Zheng, The development of binary Mg-Ca alloys for use as biodegradable materials within bone, Biomaterials. 29 (2008) 1329-1344. doi:10.1016/j.biomaterials.2007.12.021. 
[20] Q. Li, Q. Zhang, M. An, Enhanced corrosion and wear resistance of AZ31 magnesium alloy in simulated body fluid via electrodeposition of nanocrystalline zinc, Materialia. 4 (2018) 282-286. doi:10.1016/j.mtla.2018.09.038.

[21] L. Wang, T. Shinohara, B.P. Zhang, XPS study of the surface chemistry on AZ31 and AZ91 magnesium alloys in dilute $\mathrm{NaCl}$ solution, Appl. Surf. Sci. 256 (2010) 58075812. doi:10.1016/j.apsusc.2010.02.058.

[22] L.Y. Cui, X.H. Fang, W. Cao, R.C. Zeng, S.Q. Li, X.B. Chen, Y.H. Zou, S.K. Guan, E.H. Han, In vitro corrosion resistance of a layer-by-layer assembled DNA coating on magnesium alloy, Appl. Surf. Sci. 457 (2018) 49-58. doi:10.1016/j.apsusc.2018.06.240.

[23] S. Chen, J. Zhang, Y. Chen, S. Zhao, M. Chen, X. Li, M.F. Maitz,J. Wang, N. Huang, Application of Phenol/Amine Copolymerized Film Modified Magnesium Alloys: Anticorrosion and Surface Biofunctionalization, ACS Appl. Mater. Interfaces. 7 (2015) 24510-24522. doi:10.1021/acsami.5b05851.

[24] S.L. Sinebryukhov, P.P. Kushch, D.P. Kiryukhip, G.A. Kichigina, S.V. Gnedenkov, D.V. Mashtalyar, K.V. Nadaraia, V.M. Buznik, Composite coatings formed on the PEO-layers with the use of solutions of tetrafluoroethylene telomers, Surf. Coatings Technol. 346 (2018) 53-62. doi:10.1016/j.surfcoat.2018.04.036.

[25] S. Chen, S. Zhao, M. Chen, X. Zhang, J. Zhang, X. Li, H. Zhang, X. Shen, J. Wang, N. Huang, The anticorrosion mechanism of phenolic conversion coating applied on magnesium implants, Appl. Surf. Sci. 463 (2019) 953-967. doi:10.1016/j.apsusc.2018.08.261.

[26] S. Shadanbaz, G.J. Dias, Calcium phosphate coatings on magnesium alloys for biomedical applications: A review, Acta Biomater. 8 (2012) 20-30. doi:10.1016/j.actbio.2011.10.016.

[27] H. Wang, S. Zhu, L. Wang, Y. Feng, X. Ma, S. Guan, Formation mechanism of Cadeficient hydroxyapatite coating on $\mathrm{Mg}-\mathrm{Zn}-\mathrm{Ca}$ alloy for orthopaedic implant, Appl. Surf. Sci. 307 (2014) 92-100. doi:10.1016/j.apsusc.2014.03.172.

[28] L.Y. Cui, G. Bin Wei, Z.Z. Han, R.C. Zeng, L. Wang, Y.H. Zou, S.Q. Li, D.K. Xu, S.K. Guan, In vitro corrosion resistance and antibacterial performance of novel tin 
dioxide-doped calcium phosphate coating on degradable Mg-1Li-1Ca alloy, J. Mater. Sci. Technol. 35 (2019) 254-265. doi:10.1016/j.jmst.2018.09.052.

[29] Z.-L. Wang, S.-Q. Li, C.-L. Zhang, L.-Q. Shi, L.-Y. Cui, F. Zhang, R.-C. Zeng, Y.-B. Zhao, Corrosion Resistance of Silane-Modified Hydroxyapatite Films on Degradable Magnesium Alloys, Acta Metall. Sin. (English Lett. 31 (2017) 180-188. doi:10.1007/s40195-017-0601-8.

[30] M.L. Cairns, B.J. Meenan, G.A. Burke, A.R. Boyd, Influence of surface topography on osteoblast response to fibronectin coated calcium phosphate thin films, Colloids Surfaces B Biointerfaces. 78 (2010) 283-290. doi:https://doi.org/10.1016/j.colsurfb.2010.03.013.

[31] A.R. Boyd, C. O'Kane, P. O'Hare, G.A. Burke, B.J. Meenan, The influence of target stoichiometry on early cell adhesion of co-sputtered ealcium-phosphate surfaces, J. Mater. Sci. Mater. Med. 24 (2013) 2845-2861. doi:10.1007/s10856-013-5021-3.

[32] L. Winning, L. Robinson, A.R. Boyd, I.A. El Karim, F.T. Lundy, B.J. Meenan, Osteoblastic differentiation of periodontal ligament stem cells on non-stoichiometric calcium phosphate and titanium surfaces, J. Biomed. Mater. Res. Part A. 105 (2017) 1692-1702. doi:10.1002/jbm.a.36044.

[33] M.M. McCafferty, G.A. Burke, B.J. Meenan, Calcium phosphate thin films enhance the response of human mesenchymal stem cells to nanostructured titanium surfaces, J. Tissue Eng. 5 (2014) 204173141453751. doi:10.1177/2041731414537513.

[34] P. O’Hare, B.J. Meenan, G.A. Burke, G. Byrne, D. Dowling, J.A. Hunt, Biological responses to hydroxyapatite surfaces deposited via a co-incident microblasting technique, Biomaterials. 31 (2010) 515-522. doi:https://doi.org/10.1016/j.biomaterials.2009.09.067.

[35] A.R. Boyd, B.J. Meenan, N.S. Leyland, Surface characterisation of the evolving nature of radio frequency (RF) magnetron sputter deposited calcium phosphate thin films after exposure to physiological solution, Surf. Coatings Technol. 200 (2006) 60026013. doi:10.1016/j.surfcoat.2005.09.032.

[36] A.R. Boyd, H. Duffy, R. McCann, M.L. Cairns, B.J. Meenan, The Influence of argon gas pressure on co-sputtered calcium phosphate thin films, Nucl. Instruments Methods 
Phys. Res. Sect. B Beam Interact. with Mater. Atoms. 258 (2007) 421-428. doi:10.1016/j.nimb.2007.02.072.

[37] E. Komarova, V. Chebodaeva, Y. Sharkeev, M. Sedelnikova, Effect of Surface Topography and Chemical Composition on Wettability of Calcium Phosphate Coatings Formed on Ti-40Nb Alloy, Key Eng. Mater. 683 (2016) 370-376. doi:10.4028/www.scientific.net/KEM.683.370.

[38] J.-W. Hwang, E.-U. Lee, L. Jung Seok, U.-W. Jung, I.-S. Lee, S.-H. Choi, Dissolution behavior and early bone apposition of calcium phosphate-coated machined implants, J. Periodontal Implant Sci. 43 (2013) 291-300. doi:10.5051/jpis.2013.43.6.291.

[39] L.Y. Li, L.Y. Cui, L. Bin, R.C. Zeng, X.B. Chen, S.Q. Li, Z.L. Wang, E.H. Han, Corrosion resistance of glucose-induced hydrothermal calcium phosphate coating on pure magnesium, Appl. Surf. Sci. 465 (2019) 1066-1077. doi:10.1016/j.apsusc.2018.09.203.

[40] S. V. Gnedenkov, S.L. Sinebryukhov, A.G. Zavidnaya, V.S. Egorkin, A. V. Puz', D. V. Mashtalyar, V.I. Sergienko, A.L. Yerokhin, A. Matthews, Composite hydroxyapatite-PTFE coatings on Mg-Mn-Cé alloy for resorbable implant applications via a plasma electrolytic oxidation-based route, J. Taiwan Inst. Chem. Eng. 45 (2014) 3104-3109. doi:10.1016/j.jtice.2014.03.022.

[41] A.R. Boyd, C. O'Kane, B.J. Meenan, Control of calcium phosphate thin film stoichiometry using multi-target sputter deposition, Surf. Coatings Technol. 233 (2013) 131-139. doi:https://doi.org/10.1016/j.surfcoat.2013.04.017.

[42] A.R. Boyd, L. Rutledge, L.D. Randolph, B.J. Meenan, Strontium-substituted hydroxyapatite coatings deposited via a co-deposition sputter technique, Mater. Sci. Eng. C. 46 (2015) 290-300. doi:10.1016/j.msec.2014.10.046.

[43] A.R. Boyd, L. Rutledge, L.D. Randolph, I. Mutreja, B.J. Meenan, The deposition of strontium-substituted hydroxyapatite coatings, J. Mater. Sci. Mater. Med. 26 (2015) 114. doi:10.1007/s10856-014-5377-z.

[44] T. Kokubo, H. Kushitani, S. Sakka, T. Kitsugi, T. Yamamuro, Solutions able to reproduce in vivo surface-structure changes in bioactive glass-ceramic A-W3, J. Biomed. Mater. Res. 24 (2018) 721-734. doi:10.1002/jbm.820240607. 
[45] ASTM, Standard Practice for Preparing, Cleaning, and Evaluating Corrosion Test Specimens, Annu. B. ASTM Stand. i (2012) 1-9. doi:10.1520/G0001-03R11.2.

[46] E. Cor, Standard Practice for Laboratory Immersion Corrosion Testing of Metals 1, Corrosion. 72 (2004) 1-8. doi:10.1520/G0031-72R04.

[47] S. Okayama, K. Kanaya, Penetration and energy-loss theory ofelectrons in solid targets, J. Phys. D. Appl. Phys. 5 (1972) 43.

http://iopscience.iop.org/article/10.1088/0022-3727/5/1/308/pdf.

[48] I.M. Hung, W.J. Shih, M.H. Hon, M.C. Wang, The properties of sintered calcium phosphate with $[\mathrm{Ca}] /[\mathrm{P}]=1.50$, Int. J. Mol. Sci. 13 (2012) 13569 13586. doi:10.3390/ijms131013569.

[49] J.G.C. Wolke, K. van Dijk, H.G. Schaeken, K. de Groot, J.A. Jansen, Study of the surface characteristics of magnetron-sputter calcium phosphate coatings, J. Biomed. Mater. Res. 28 (n.d.) 1477-1484. doi:10.1002/jbm.820281213. 